\title{
INFARTO CEREBRAL EM DUAS CRIANÇAS INFECTADAS PELO HIV-1
}

\author{
Cristiane Rocha ${ }^{1}$, Aída T. B. Gouvêa ${ }^{2}$, Daisy M. Machado², \\ Lorena Hörnke², Regina C. M. Succi ${ }^{3}$.
}

\begin{abstract}
RESUMO - Os quadros vasculares são incomuns não somente nos pacientes adultos (1\%) como também nas crianças. Nosso objetivo é alertar para a possibilidade da infecção pelo HIV-1 em crianças com manifestações cerebrovasculares. Das 204 crianças infectadas pelo HIV acompanhadas no Ambulatório de SIDA, descrevemos dois pacientes pré-escolares do gênero masculino, com quadro agudo febril, rebaixamento do nível deconsciência, status epilepticus e hemiparesia como primeira manifestação de infecção pelo HIV-1. Nos dois casos evidenciouse extensa isquemia em território da artéria cerebral média. Um dos pacientes evoluiu com tetraparesia espástica grave, sem contactuar com o meio, epilepsia parcial e óbito 4 anos após o diagnóstico, sem melhora do quadro neurológico. O outro paciente apresentou hemiparesia direita e afasia global, evoluindo com regressão completa do quadro neurológico. A infreqüência desses achados torna importante o seu relato, visando a inclusão da infecção pelo HIV-1 no diagnóstico diferencial das quadros cerebrovasculares na criança.
\end{abstract}

PALAVRAS-CHAVE: isquemia, criança, HIV-1, imunodeficiência adquirida.

\begin{abstract}
Ischaemic stroke in two children with HIV-1
ABSTRACT - Cerebral ischaemia caused by inflammatory vasculopathies has been described as a complication of human immunodeficiency virus (HIV) infection. The goal of our study is to report two cases of pediatric human immunodeficiency virus infection and cerebrovascular manifestations. We describe two pre-school boys, from a group of 204 outpatients, who presented fever, seizures, hemiparesis and impairment of conscience level as a first symptom of HIV-1 infection. The serial imaging studies revealed infarction of middle cerebral artery in both cases. The first one child had a severe spastic tetraparesis and partial epilepsy and died four years later without any improvement despite of the antiretroviral therapy. The second patient had a right hemiparesis and global aphasia totally recovered two years later with antiretroviral and rehabilitation therapies. HIV infection should be included in differential diagnosis of children who present with seizures, mental status change or focal neurological deficits and seizures.
\end{abstract}

KEY WORDS: stroke, infance, HIV-1.

O vírus da imunodeficiência humana (HIV-1) invade o sistema nervoso central (SNC) possivelmente na 2a semana pós-infecção e $30 \%$ a $80 \%$ das crianças acometidas pelo vírus podem ter sinais clínicos desse comprometimento ${ }^{1-5}$. Em adultos, os quadros vasculares secundários à infecção pelo HIV-1 são raros, sendo sua incidência próxima a $1 \%$. Segundo Shah e col. ${ }^{6}$, em crianças essa incidência é de 1,3\% ${ }^{6}$.

Descreveremos duas crianças infectadas pelo HIV1 que inauguraram o quadro de imunodeficiência adquirida com o acidente vascular cerebral, a fim de realçar a importância dessa infecção no diagnóstico diferencial das isquemias cerebrais na infância. O primeiro caso foi estudado por revisão de prontuário, mas as imagens foram perdidas. O segundo caso tem termo de consentimento assinado e pertencem a ele as imagens deste artigo.

\section{CASOS}

Caso 1. JDP, menino de 2anos, que deu entrada no pronto socorro em status epilepticus generalizado, febre e sinais meníngeos. Evoluiu para o coma havendo dificuldade de controle das crises epilépticas com medicação anticonvulsivante. Tomografia de crânio (TC) por ocasião da admissão mostrava extenso edema no hemisfério cerebral direito com desvio de linha média para a esquerda, o liquor (LCR) apresentava 55 células (75\% linfócitos, $22 \%$ neutrófilos, $13 \%$ monócitos), glicose- $63 \mathrm{mg} / \mathrm{dL}$, proteínas$62 \mathrm{mg}$. O exame de LCR $12 \mathrm{~h}$ depois manteve padrão viral

\footnotetext{
${ }^{1}$ Neuropediatra do Hospital Santa Marcelina (São Paulo SP, Brasil) e do Ambulatório de AIDS-Pediatria-UNIFESP (São Paulo SP, Brasil); 2Médico Pediatra do Ambulatório de AIDS-Pediatria-UNIFESP; ${ }^{3}$ Professora Adjunta da Disciplina de Infectologia, Departamento de Pediatria UNIFESP.
}

Recebido 21 Março 2003, recebido na forma final 20 Junho 2003. Aceito 8 Julho 2003.

Dra. Cristiane Rocha - Rua. Nicolau de Souza Queiroz 406/114 - 04105-001 São Paulo SP - Brasil. E-mail: cri.rocha2@ig.com.br 
e o segundo exame de TC evidenciava extensa área hipodensa em toda região de projeção da artéria cerebral média direita, sugestiva de isquemia. Foi feita suspeita diagnóstica de meningencefalite herpética apesar de não haver história prévia de infecções por herpes e seus subtipos e iniciado tratamento com aciclovir. Nesse momento foi feito o diagnóstico da síndrome da imunodeficiência adquirida (SIDA). No transcorrer da evolução foram constatados sepse e grave quadro pulmonar, tendo sido associados antibióticos de largo espectro. A cultura de LCR foi negativa para BK, Herpesvirus e agentes bacterianos. Permaneceu em coma por mais de três semanas, apresentando também crises parciais motoras com generalização secundária. O eletroencefalograma (EEG) mostrava alentecimento difuso com ondas agudas bilaterais de predomínio temporal. Recebeu alta hospitalar após 90 dias de internação, sem contactuar, com tetraparesia espástica em uso de terapia antiretroviral e carbamazepina. A TC de crânio, um ano após o início do quadro, mostrava intensa atrofia cortico-subcortical, de predomínio à direita com dilatação ventricular ipsilateral; o EEG apresentava espículas e ondas agudas difusas, bilateralmente, com predomínio occipital esquerdo. Quatro anos após esse evento, o menor faleceu em conseqüência de grave insuficiência respiratória, sem haver apresentado melhora do quadro neurológico.

Caso 2. Menino de 3 anos que deu entrada no pronto socorro em status epilepticus generalizado, febre e sinais meníngeos. LCR e TC de crânio na admissão foram normais. Novo LCR realizado 8 horas após a admissão continuava normal. Foi iniciado aciclovir por suspeita diagnóstica de meningencefalite herpética. Não havia história prévia de infecção pelos herpes-virus. $O$ paciente evoluiu com crises parciais motoras com generalização secundária e hemiparesia direita. O estudo da TC de crânio, 7 dias após, mostrava extensa área hipodensa frontoparieto-temporal esquerda e discreta área hipodensa parietal direita; o EEG evidenciava ondas lentas em região frontotemporal esquerda; o exame de LCR foi negativo para BK, Herpes e agentes bacterianos. Nesse mesmo período foi feito o diagnóstico de infecção pelo HIV-1. Em cinco dias encontrava-se vigil, com hemiparesia direita, afasia mista, sendo constatada nítida regressão do desenvolvimento neuropsicomotor. Recebeu alta 20 dias após, sem crises epilépticas, com hemiparesia direita e afasia mista. Iniciou terapia antiretroviral um mês após a alta. Há dois anos vem apresentando bom desempenho escolar, linguagem adequada, está livre de crises epilépticas e sem medicação anticonvulsivante, tendo exame neurológico normal. Os exames de ressonância magnética de encéfalo (RM), feitos no 10 dia e 3 anos após o ictus, mostram lesões sugestivas de gliose cortico-subcortical em substâncias branca e cinzenta fronto-temporo-parietal, com atrofia cortico-subcortical parietal esquerda, bem como discreta área de gliose à direita, (Figs 1 e 2).

\section{DISCUSSÃO}

Embora infrequentes (incidência em torno de $1 \%$ ), acidentes vasculares cerebrais (AVC) podem inaugurar o quadro da SIDA em crianças infectadas pelo HIV-1. Estudos post-mortem mostram que essa ocorrência pode variar entre 4 e $29 \%{ }^{4,6}$. O diagnóstico diferencial entre vasculopatia inflamatória e outras causas de AVC é difícil na criança, sendo mais frequentes: quadros hemorrágicos secundários a trombocitopenia ou quadros isquêmicos secundários a arteriopatias, aneurismas, herpes vírus ou por lesão direta do HIV-1, levando a vasculopatia específica ${ }^{7}$. $\mathrm{Na}$ vasculopatia inflamatória parece ocorrer infecção de células endoteliais vasculares pelo agente etiológico, podendo cursar com ou sem calcificação.

Vários autores afirmam que infecções sistêmicas prévias, bacterianas ou virais, têm relação temporal

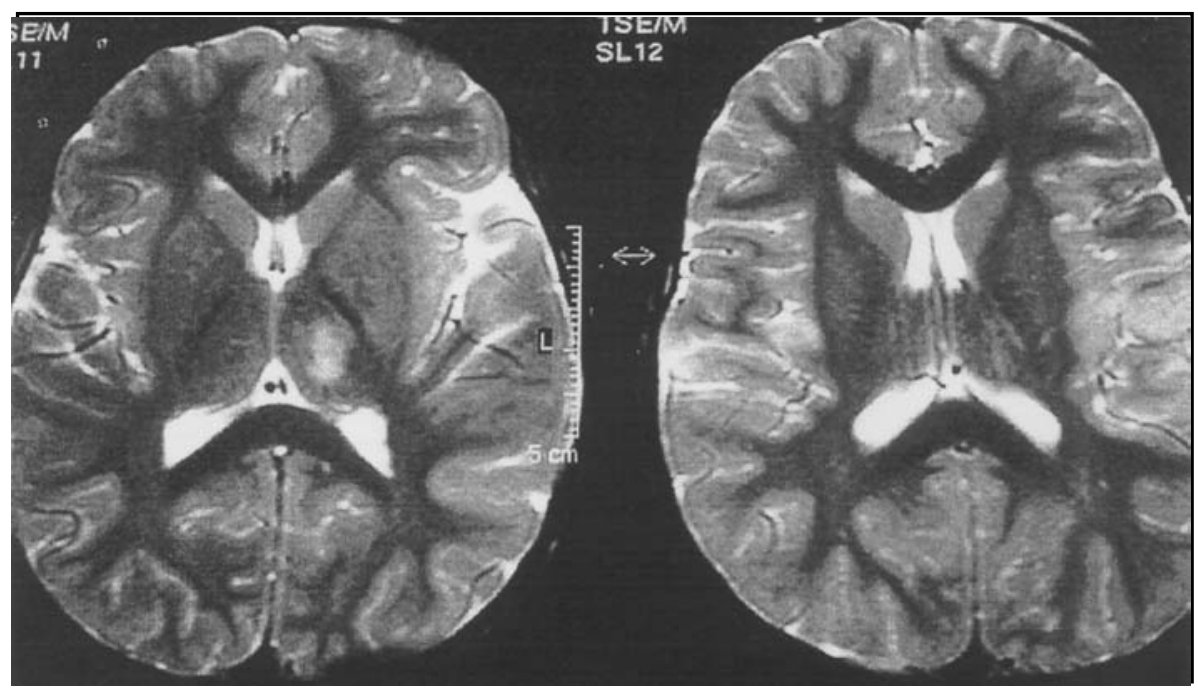

Fig 1. Paciente 2. Duas imagens sequenciadas de RM de encéfalo ponderada em T2 com hiperintensidade em regiões parietais e tálamo à esquerda no 10 이a após ictus. 


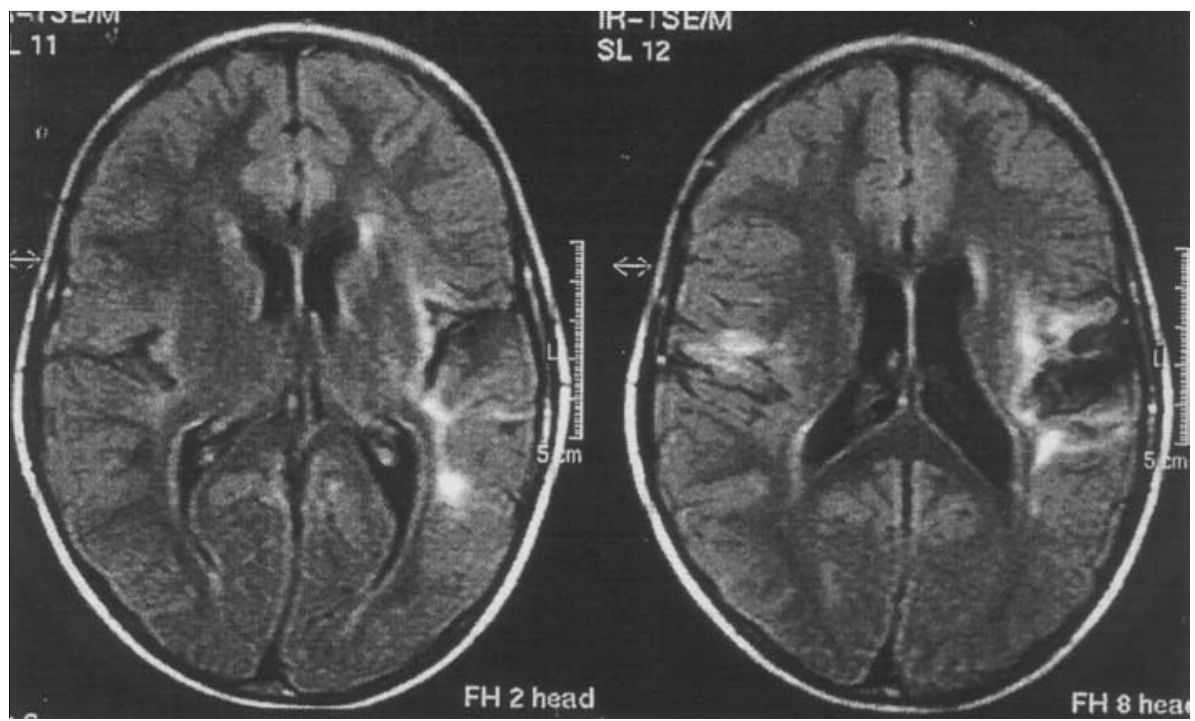

Fig 2. Paciente 2. duas imagens seqüenciadas de RM de encéfalo ponderada em flair com área de gliose parietal bilateral 2 anos após ictus.

com posterior isquemia cerebral|6,8,9. Joshi e cols. ${ }^{8}$ sugerem que infecções de repetição podem desencadear lesões na lamina elastica dos vasos intracerebrais. Shah e cols. ${ }^{6}$ postulam que o processo inflamatório comece na camada adventícia e envolva a vasa vaso rum, levando à isquemia da parede arterial, resultando na destruição da lamina elastica e fibrose da camada subintima. Também podem ocorrer dilatações aneurismáticas, esclerose ou estenoses arteriais de acometimento localizado ou difuso.

$O$ vírus da varicela zoster (VZV) é comumente descrito como causa de AVC em portadores do HIV-1, mas na maioria das vezes há história prévia de zoster cutâneo, o que não ocorreu em nossos dois pacientes ${ }^{6,10,11}$. O VZV acomete preferencialmente o território das artérias cerebrais anterior e média, na região próxima ao polígono de Willis, de modo semeIhante ao que ocorreu com o Paciente 2. Pode comprometer grandes ou pequenos vasos, provocando misto de isquemia/desmielinização cuja localização é próxima à junção da substancia branca/cinzenta ${ }^{10}$.

Narayan e cols ${ }^{12}$ descrevem o caso de uma adolescente de 13 anos infetada pelo HIV-1 com crises parciais e hemiparesia. Sua angiografia evidenciou oclusão progressiva da artéria cerebral média esquerda e de ambas as artérias cerebrais anteriores, possivelmente resultantes de lesão direta do HIV-1. Não encontramos outros casos descritos em faixa etária menor.

Em geral, o esclarecimento da causa de AVC em portadores do HIV-1 não chega a $50 \%$ dos casos $^{13}$. Nesse caso, o tratamento deve ser orientado basicamente pelo quadro clínico do paciente.
A relação entre infecção e hemiparesia de origem vascular foi descrita pela primeira vez por Marie em 1885; em 1897 Freud também descreve caso semelhante ${ }^{10}$. Passados mais de cem anos, essa relação encontra-se bem estabelecida, mas a confirmação etiológica ainda é difícil. Disso advém o interesse dos autores na descrição desses casos, enfatizando a associação entre HIV-1 e manifestações cerebrovasculares, lembrando a necessidade de investigar esse agente em crianças com quadros vasculares sem etiologia claramente esclarecida.

\section{REFERÊNCIAS}

1. Belman A. Neuro AIDS: infants, children and adolescents. Am Neurol Acad, Syllabus 1996, vol IX

2. Cinque P, Vagol A, Ceresa D, et al. Cerebrospinal fluid HIV RNA levels: correlation with HIV encephalitis. AIDS 1998;12:389-394.

3. SAAG M. Use of HIV viral load in clinical pratice: back to the future. Ann Int Med 1997;126:983-985.

4. Connor MD, Lammie GA, Bell JE, Warlow CP, Simmonds P, Brettle RD. Cerebral infarction in adults AIDS patient: observations from the Edinburgh HIV autopsy cohort. Stroke 2000;31:2117-2126.

5. Pediatric European Network Treatment of Aids (Penta).HIV viral load and CD4 cell count in untreated children with vertically acquired asyntomatic or mild disease. AIDS 1998;12:1-8.

6. Shah SS, Zimmerman RA, Rorke LB, Vezina LG. Cerebrovascular complications of HIV in children. AJNR1 1996;17:1913-1917.

7. FerrerA PC, Curran CB, Swanson H. Etiology of pediatric isquemic stroke. Am J Emerg Med 1997;15:671-679.

8. Joshi VV, Pawelb, Connor E. Arteriopathy in children with acquired immune deficiency syndrome. Pediatr Pathol 1987;7:261-275.

9. Grau AJ, Buggle F, Becher $\mathrm{H}$, et al. Recent bacterial and viral infection is a risk factor for cerebrovascular ischemia. Neurology 1998;50:196-203.

10. Kleinschmidt-DeMasters BK, Amlie-Lefond C, Filden DH. The patterns of varicella zoster virus encephalitis. Hum Pathol 1996;27:927-938.

11. Berkefeld J, Enzensberg W, Lanfermann H. Mri human immnodeficiency virus-associated cerebral vasculitis. Neuroradiology 2000; 42:526-528

12. Narayan P, Samuels OB, Barrow DL. Stroke and pediatric human immunodeficiency virus infection: case report and review of the literature Pediatr Neurosurg 2002;37:158-163.

13. Picard O, Brunereau L, Pelosse B, Kerob D, Cabane J, Imbert JC. Cerebral infarction associated with vasculitis due to varicella zoster virus in patient infected with human immunodeficiency virus. Biomed \& Pharmacother 1997;51:449-454. 